INVESTIGACIÓN

Recibido: 27/08/2018 --- Aceptado: 08/04/2019 --- Publicado: 15/09/2019

\title{
ANÁLISIS DE LAS ABREVIATURAS COMUNICACIONALES DEL LENGUAJE ESCRITO EN LA RED SOCIAL FACEBOOK
}

\section{Analysis of the communicational abbreviations of the written language in the Facebook social network}

Jonathan Sabando Rendón ${ }^{1}$. Universidad de Guayaquil. Ecuador. jonathan.sabandor@ug.edu.ec

Tomás Rodríguez Caguana. Universidad de Guayaquil. Ecuador. tomas.rodriguezc@ug.ec

\section{RESUMEN}

Esta investigación analiza las configuraciones gramaticales implementadas en la construcción de mensajes del lenguaje escrito, a través de la red social Facebook en un grupo de 100 estudiantes, el problema a investigar se definió: ¿Cuál es el impacto de la red social Facebook en el uso de abreviaturas comunicacionales del lenguaje escrito en los estudiantes de segundo y tercero bachillerato de la Unidad Educativa Pedro J. Montero? Objetivo General: estudiar la incidencia de las abreviaturas comunicacionales del lenguaje escrito en la red social Facebook. Hipótesis: los factores que inciden en el uso de abreviaturas comunicacionales del lenguaje escrito en la red social Facebook son el uso del chat como medio de comunicación virtual y la inmediatez en la codificación del mensaje. Variables: lenguaje escrito y Comunicación virtual. Tipo: descriptivo. Diseño: no experimental-transeccional. Metodología: empirismo. Técnicas: cuatro cualitativas y cuatro cuantitativas. Muestra: no probabilística-por cuota. Resultados: hipótesis comprobada.

PALABRAS CLAVE: comunicación - lenguaje escrito - configuración gramatical comunicación virtual - ciberlenguaje - redes sociales - Facebook - interacción virtual abreviaturas.

\section{ABSTRACT}

This research analyzes the grammatical configurations implemented in the construction of written language messages, through the social network Facebook in a group of 100 students, for which the problem to be investigated was defined: what is the impact of

${ }^{1}$ Jonathan Sabando Rendón: Licenciado en Ciencias de la Comunicación Social de la Universidad de Guayaquil. 
the social network Facebook on the use of communication abbreviations of language written in the second and third year students of the Pedro J. Montero Educational Unit? General Objective: to study the incidence of communicational abbreviations of the written language on the social network Facebook. Hypothesis: The factors which influence on the use of communication abbreviations of the written language in the social network are the use of chat as a means of virtual communication and the immediacy in coding of the message. Variables: written language and virtual communication. Type: descriptive. Design: no-experimental-transectional. Methodology: empiricism. Techniques: four qualitative and four quantitative. Sample: not probabilistic-per quota. Results: hypothesis was approved.

KEY WORDS: communication - written language - grammar configuration - virtual communication - cyberlanguage - social networks - Facebook - virtual interaction abbreviations.

\section{ANALISES DAS ABREVIATURAS COMUNICACIONAIS DA LIGUAGEM ESCRITA NA REDE SOCIAL FACEBOOK}

\section{RESUME}

Esta investigação analisa as configurações gramaticais implementadas na construção de mensagens da linguagem escrita através da rede social Facebook em um grupo de 100 estudantes, o problema investigado define-se: Qual e o impacto da rede social Facebook no uso de abreviaturas comunicacionais da linguagem escrita nos estudantes de segundo e terceiro ano da Universidade Educativa Pedro J. Montero? Objetivo geral: estudar a incidência das abreviaturas comunicacionais escritas na rede social Facebook. Hipóteses: os fatores que incidem no uso de abreviaturas comunicacionais da linguagem escrita na rede social Facebook são o uso do chat como meio de comunicação virtual e a rapidez na codificação da mensagem. Variáveis: linguagem escrita e Comunicação virtual. Tipo: descritivo. Desenho: não experimental - transeccional. Metodologia: empirismo. Técnicas: quatro qualitativas e quatro quantitativas. Mostra: não probabilística - por cota. Resultados: hipótese comprovada.

PALAVRAS CHAVE: comunicação - linguagem escrita - configuração gramatical comunicação virtual - ciberlinguagem - redes sociais - Facebook - interação virtual abreviaturas.

\section{Como citar el artículo:}

Sabando Rendón, J. y Rodríguez Caguana, T. (2019). Análisis de las abreviaturas comunicacionales del lenguaje escrito en la red social Facebook. [Analysis of the communicational abbreviations of the written language in the Facebook social network]. Vivat Academia. Revista de Comunicación, 148, 41-55. 
DOI: http://doi.org/10.15178/va.2019.148.41-55

Recuperado de http://www.vivatacademia.net/index.php/vivat/article/view/1132

\section{INTRODUCCIÓN}

En el mundo contemporáneo, usuarios que pertenecen a una red social envían millones de mensajes al día. En ellos, se ha manifestado un cambio lingüístico al momento de escribir, que no corresponde a la regida por las reglas gramaticales, aunque esto no quiere decir, que quienes receptan esa información no la puedan comprender.

Tal como se expresa en el artículo Ciberlenguaje juvenil en las redes sociales, "esta forma de escribir no produce problemas de comunicación al destinatario de los mensajes (los textos son coherentes y cohesionados porque los destinatarios de los mensajes comparten las mismas competencias)" (Vaqueiro, 2012, p. 4). La comunicación que sostienen los usuarios en la red, pese a no tener una estructura gramatical lógica, mantiene el sentido del mensaje, porque tanto el emisor como el receptor, manejan el mismo código lingüístico. Es por ello que, la mayoría de los jóvenes, han ido modificando su manera de escribir, haciendo de esto, una práctica diaria de varios símbolos erróneos, que van siendo parte de su educación regular.

Esta "jerga utilizada en la red por estos usuarios no especializados es el ciberlenguaje, es decir el lenguaje de géneros como el 'chat' y los mensajes enviados por teléfono móvil, que se caracteriza por recurrir a las abreviaturas de modo poco canónico". (Berlanga y Martínez, 2010, p. 51). Las abreviaturas empleadas en la red son denominadas ciberlenguaje y, su utilización, proviene desde el envío de mensajes de texto de telefonía móvil.

Por su parte, en el texto Oralidad y escritura. Tecnologías de la palabra, se define al lenguaje escrito como:

Un sistema codificado de signos visibles por medio del cual un escritor podía determinar las palabras exactas que el lector generaría a partir del texto. (...) las marcas codificadas visibles integran las palabras de manera total, de modo que las escrituras y referencias sutilmente intrincadas que se desarrollan en el oído pueden ser captadas en forma visible exactamente en su complejidad específica. (Ong, 2006, p. 87).

La representación del lenguaje escrito guarda tanta complejidad como las implicadas en la transmisión del mensaje a través del sonido. Ong, define a la escritura como un proceso de codificación de signos visibles, que permite al receptor captar el mensaje que plasma el emisor, mediante el uso del lenguaje que comparten ambos individuos. Es por ello, que las articulaciones de los códigos emitidos de forma verbal, son manifestadas de manera ortográfica $y$, son percibidas de manera óptica, para la decodificación y entendimiento de la información. Por otro lado, la escritura se aprende mediante un proceso de instrucción especializada, la misma que requiere

Vivat Academia. Revista de Comunicación. 15 septiembre 2019 /15 diciembre 2019, nº 148, 41-55 
tiempo y práctica "en contraste con la oralidad, la escritura es completamente artificial, no hay manera de escribir 'naturalmente'. Esto se debe a que la escritura está regida por unas reglas que han sido ideadas conscientemente y son, por tanto, definibles" (Rincón, 2011, p. 74).

El artículo, Uso y consumo de redes sociales virtuales entre estudiantes universitarios. Un acercamiento a los hábitos de multitarea de la Revista Iberoamericana de Producción Académica y Gestión Educativa, explica el cambio de la forma de comunicación con el surgimiento tecnológico.

Con la llegada del siglo XXI, las formas de comunicación e interacción entre los individuos cambiaron de manera importante. En ciertos contextos socioeconómicos y socioculturales, ya no sólo se mantiene contacto con las personas de manera directa (física, interpersonal, cara a cara), sino que también se ha conseguido entablar una interacción de manera virtual con la mediación de tecnologías digitales, gracias a recursos electrónicos como la telefonía móvil e Internet. (Cortés, 2015, p. 3).

El avance de la tecnología ha llevado que la comunicación encuentre nuevos medios y canales de información, por medio del cual, la presencia del emisor y perceptor en tiempo y espacio, pasó a segundo plano (en cierta manera), tal cual como se señala en el artículo Comunicación interpersonal en la web 2.0., por lo cual "la comunicación mediada por ordenador facilita una mayor diversidad de intercambios comunicativos, generando nuevas posibilidades que permiten modificar las relaciones tradicionales". (Zapatero et al., 2013, p. 441).

Esto hace que las redes sociales sean "fuente de recursos que son utilizados para cubrir necesidades, tanto de índole psicológica como social". (Colás et al., 2013, p. 17) lo que les permite mantener una relación basada en la dinamización de los contenidos, donde los jóvenes manifiestan sus necesidades emocionales y las jóvenes las utilizan como medio para generar una relación.

Por su parte, el uso de la escritura dentro de las redes sociales tiene variaciones, debido a las limitaciones temporales que tiene el sujeto, adaptando la ortografía, con alteraciones gramaticales, la misma que le permiten un rápido envío de mensajes. Como se muestra en la tabla extraída del texto, Lenguajes del poder. El chat en las redes sociales virtuales: lenguaje y libertad:

Tabla 1. Lenguajes del poder. El chat en las redes sociales virtuales: lenguaje y libertad.

\begin{tabular}{|l|l|}
\hline Forma correcta & Forma moderna (chat) \\
\hline Hola & Ola \\
\hline Pues & Ps \\
\hline Bien & Bn \\
\hline Como & Km \\
\hline Que & Ke Q \\
\hline Usted & Ud \\
\hline Quien & Kien \\
\hline Por que & Xq \\
\hline
\end{tabular}

Fuente: (Gonzáles y González, 2014, p. 63).

Vivat Academia. Revista de Comunicación. 15 septiembre 2019 /15 diciembre 2019, nº 148, 41-55 
En la tabla se observa el cambio gramatical que emplean las personas en la escritura dentro de la red, la cual supone una vaguedad del individuo al momento de representar las palabras, construyendo nuevos signos y símbolos. A su vez, la significación del mensaje sigue manteniendo el sentido dado, con la diferencia que los gráficos utilizados, son alterados, reduciendo la palabra a la menor posibilidad de expresión posible, "Los adolescentes, para comunicarse en Facebook, han generado una serie de códigos nuevos de escritura, que no tienen en cuenta la gramática y las reglas ortográficas, sino que obedecen a otras condiciones como la velocidad de escritura y especialmente las estéticas digitales" (Almansa, 2013, p. 129).

Facebook, al igual que permite una rápida difusión de información, ha generado cambios en el empleo de la gramática, la misma que se debe -por lo general- a la rapidez con la que se escribe. La utilización de estos nuevos símbolos gramaticales, no se rigen por las normativas de la escritura, pero su manejo, no altera la significación del contenido de la información. Ante esta forma de codificación "se planteó la posibilidad de que hubiera nacido un nuevo código; sin embargo, pronto quedó comprobado que no se trataba más que de la abreviación, recreación o recodificación del ya existente". (Fernández, 2016, p. 3).

El lenguaje escrito empleado en la red ha ido variando, llegando a simplificar las palabras de tal manera que se expresen con el menor uso de caracteres, sin perder el sentido del mensaje, construyendo así otra manera de codificación. Un claro ejemplo de la utilización del ciberlenguaje, se visualiza en la figura del artículo, el lenguaje chat 'rejuvenece', pero supone riesgos al idioma.

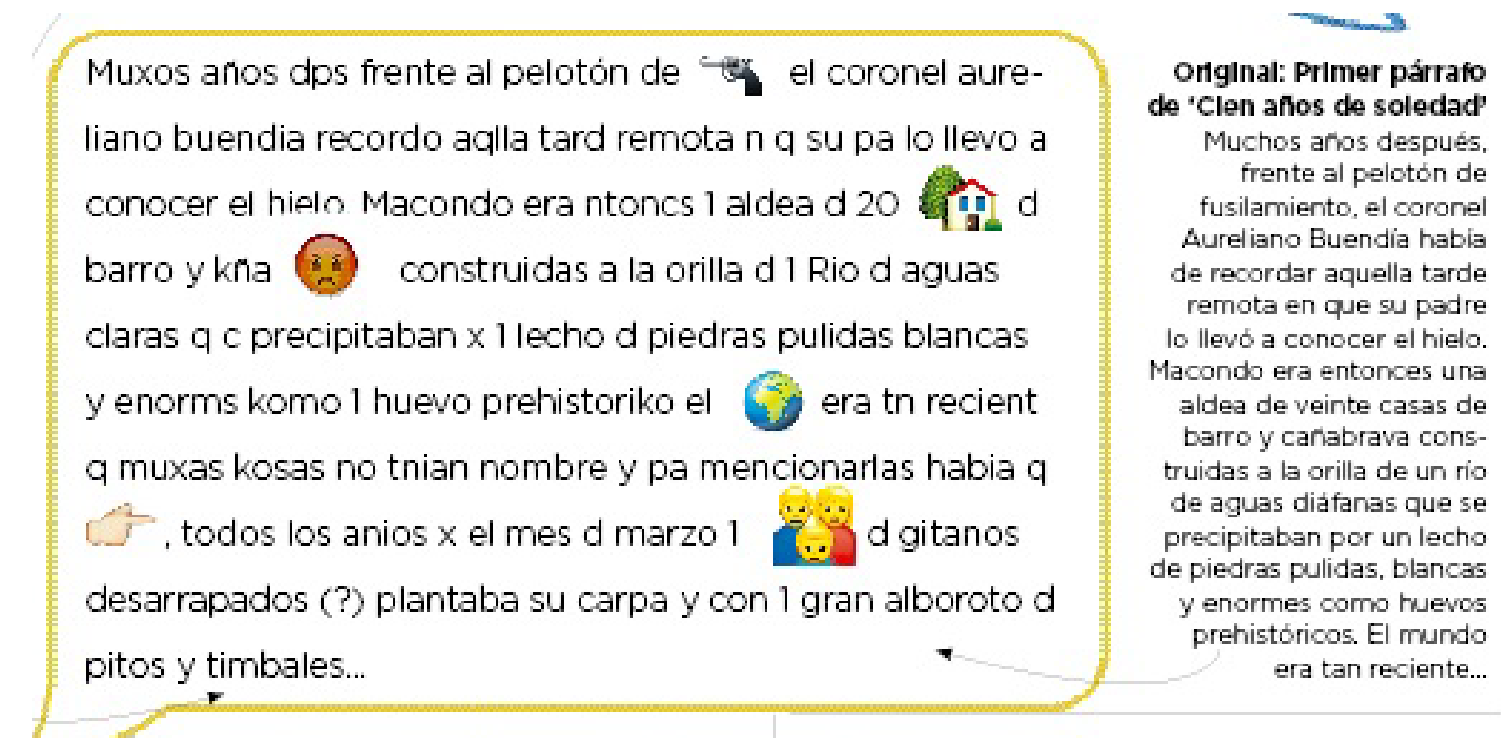

Figura 1: El lenguaje chat 'rejuvenece', pero supone riesgos al idioma.

Fuente: Ríos, 2016.

Vivat Academia. Revista de Comunicación. 15 septiembre 2019 /15 diciembre 2019, nº 148, 41-55 
Las palabras presentan alteraciones gramaticales que, a primera instancia, no transmiten un mensaje significativo para quienes no conocen esa manera de codificar, pero el mensaje mantiene su estructura sintáctica, para los que comparten esa escritura.

Esa forma de simbolizar, cuya finalidad es la de agilizar la graficación de mensajes entre los participantes de las redes sociales, guarda el sentido de la información construida en su mínima expresión. Es por ello que, con el auge de las redes sociales, su uso se ha incrementado, manejando una manera de codificación que tiene al lenguaje escrito como base, para la simbolización de los mensajes.

Asimismo, el uso de los emojis en conjunción con frases, forman parte del ciberlenguaje, como se detalla en el artículo, La socialización mediada en las interacciones juveniles. La construcción del Yo en Facebook.

El uso de emoticonos, las abreviaciones y otros aspectos como el intercambio de letras, repetición de las mismas, así como el uso de signos de interrogación y admiración, dan vida a un estilo digital mejor conocido como 'ciberlenguaje' que emplea nuevos códigos y se caracteriza por no diferenciar entre habla y la escritura, es decir, un estilo en donde se escribe como se habla (Pérez; Ibarra, 2013, p. 10).

Los autores, describen al ciberlenguaje como la mutación de la gramática, donde se utilizan simbologías gráficas que, además de expresar la información, describen el estado de anímico del sujeto. De la misma manera, se explica que es una manera donde la ortografía está basada en como el sujeto se expresa oralmente. Estas variantes en la grafía, vienen acompañada por alteraciones en las palabras y símbolos, que constituyen y guardan un mensaje, donde el descifrado, se basa en el aprendizaje y práctica de ese lenguaje. En la imagen extraída del apartado, Ciberlenguaje: $Q$ sean :) s/ importar en q idioma, se visualiza:
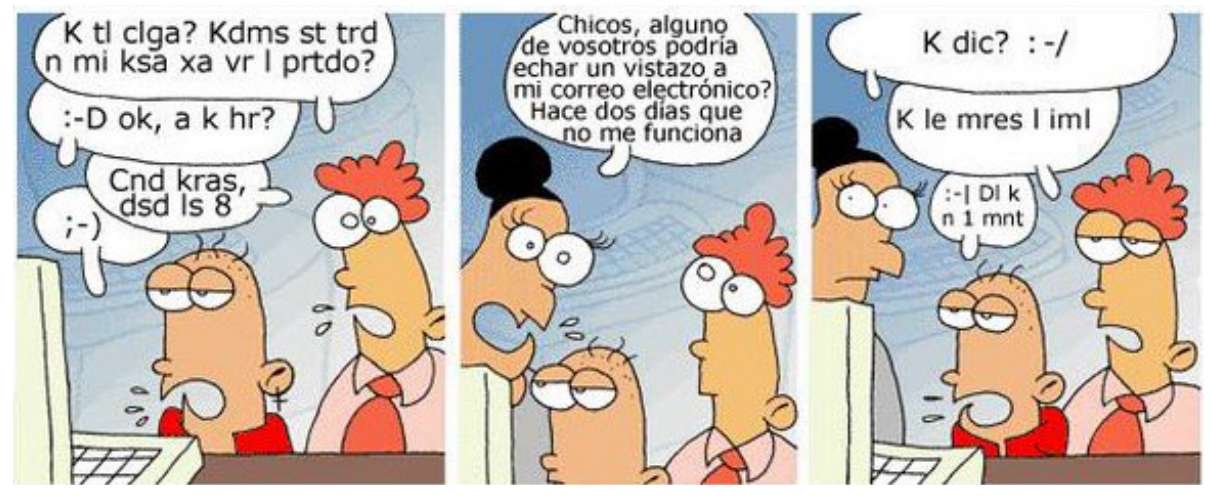

Figura 2: Ciberlenguaje: $Q$ sean :) s/ importar en q idioma.

Fuente: Carbone, 2016.

Vivat Academia. Revista de Comunicación. 15 septiembre 2019 /15 diciembre 2019, nº 148, 41-55 
Como se observa, el estilo de expresión del ciberlenguaje es un código compuesto por mutaciones léxicas, que únicamente son comprensibles por quienes comparten el mismo signo lingüístico. De la misma forma, la manera de graficar el mensaje está ligado a la forma de hablar que tiene el sujeto, es decir, un vínculo compartido entre la oralidad y la ortografía.

El lenguaje utilizado en la red social Facebook, es una manera simplista de comunicación, en la que se emplean palabras sencillas que envían un mensaje más directo y rápido. "Su objetivo es hacer la comunicación más expresiva, atractiva, flexible, lúdica e incluso más elocuente; su uso es deliberadamente coloquial, por ello es que captura algunos elementos de la oralidad (...) es una nueva forma de comunicación con sus propios códigos que borra los límites entre oralidad y escritura". (Rodríguez, 2015, p. 22).

Por lo que el ciberlenguaje, es utilizado de una manera informal, donde la imaginación para expresar un mensaje de forma reducida, es la base para la construcción de los nuevos códigos simbolizados por medio de la abreviatura de palabras.

\section{OBJETIVOS}

Estudiar los factores que inciden en el uso de las abreviaturas comunicacionales del lenguaje escrito en la red social Facebook en los estudiantes de segundo y tercero bachillerato de la Unidad Educativa Pedro J. Montero.

\section{METODOLOGÍA}

Este trabajo tiene un diseño de investigación no experimental-transeccional, porque las variables que se utilizan para analizar a las abreviaturas comunicacionales de la red social Facebook no se modifican. Además, que el tiempo de abordaje de la unidad de observación es de seis meses. Este trabajo tiene un tipo de investigación descriptivo, pues se describen las variables e indicadores que se utilizan para analizar a las abreviaturas comunicacionales de la red social Facebook, donde se desglosa su contenido sin realizar un ejercicio estadístico comparativo. Este estudio se fundamenta bajo la escuela filosófica empirista, pues el conocimiento del ser humano, se adquiere a través de la experiencia. Es por ello, que la abreviación dada al lenguaje comunicativo en la red social Facebook, se desarrolla mediante la práctica.

\subsection{Hipótesis}

Los factores que inciden en el uso de abreviaturas comunicacionales del lenguaje escrito en la red social Facebook son el uso del chat como medio de comunicación virtual y la inmediatez en la codificación del mensaje.

Vivat Academia. Revista de Comunicación. 15 septiembre 2019 /15 diciembre 2019, nº 148, 41-55 
Tabla 2. Definición operacional de las variables.

Hipótesis:

fos factores que inciden en el uso de abreviaturas comunicacionales del lenguaje escrito en la red social Facebook por los estudiantes de segundo y tercero bachillerato de la Unidad Educativa Pedro J. Montero son el uso del chat como medio de comunicación virtual y la inmediatez en la codificación del mensaje.

Variable:

Dimensión:

Indicador:

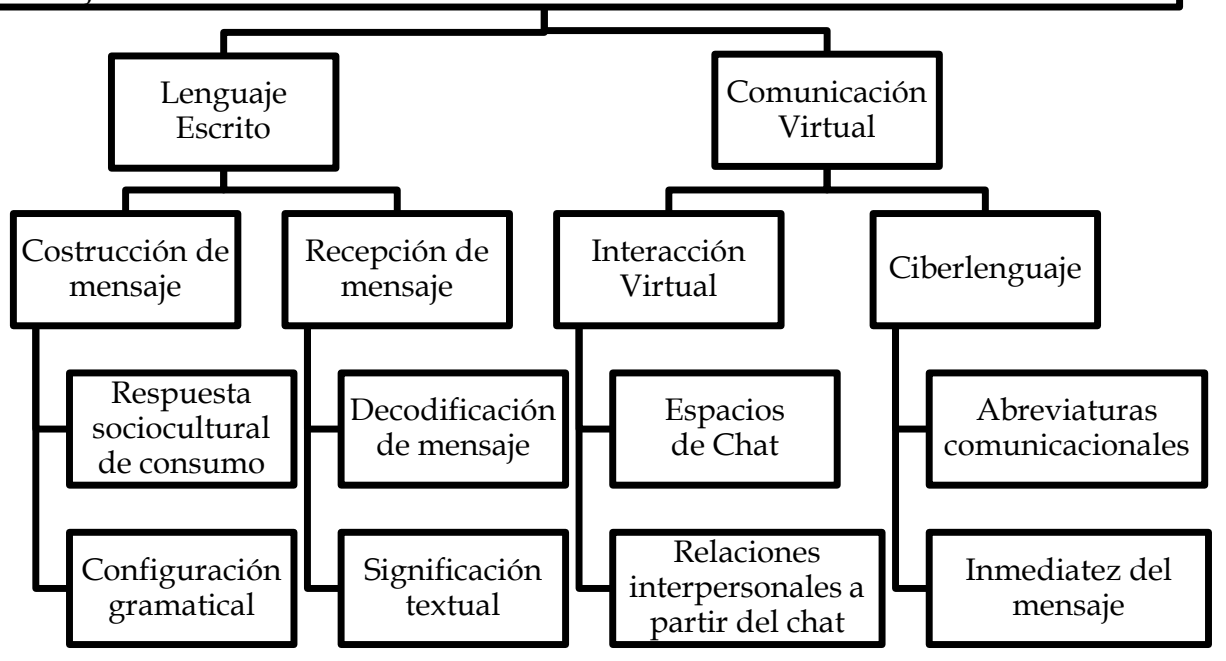

Fuente: Elaboración propia.

\subsection{Técnicas de investigación aplicadas}

Luego del desarrollo del desglose de las variables en dimensiones e indicadores, en este trabajo se seleccionaron las técnicas de investigación pertinentes para abordar al público muestral. Por lo que a continuación se detallan las técnicas utilizadas:

Investigación bibliográfica: esta técnica de investigación, fue empleada para la recolección de información científica que aporte al estudio de las abreviaturas comunicacionales del lenguaje escrito.

Entrevista abierta: se usó para conocer cómo ha afectado el uso del chat en la codificación de mensajes y los problemas gramaticales que genera.

Test proyectivo: empleada para determinar, por medio de imágenes, el uso de abreviaturas comunicacionales en la construcción textos y la decodificación del público muestral.

Situación ideal: utilizada para obtener información sobre cuál sería el modelo gramatical que se use en la comunicación escrita.

Vivat Academia. Revista de Comunicación. 15 septiembre 2019 / 15 diciembre 2019, n 148, 41-55 
Cambio de rol: esta técnica fue empleada para determinar la respuesta sociocultural de consumo de las abreviaturas comunicacionales y el empleo en las relaciones interpersonales a partir del chat.

Encuesta: fue utilizada para cuantificar el uso de abreviaturas comunicacionales en la red social Facebook.

Escala de Likert: se usó para determinar la respuesta sociocultural de consumo de las alteraciones de las palabras como forma de construcción de mensajes.

Escala de puntos: fue utilizada para conocer la utilidad del chat como medio generador de relaciones interpersonales por medio del Facebook.

Escala de intensidad: esta técnica de investigación fue empleada para determinar los espacios de chat y la interacción del público muestral.

\subsection{Población y muestra}

Esta investigación cuenta con una población de 159, para la cual la muestra seleccionada para este trabajo es no probabilística-por cuota, pues se enfoca en un público muestral que conoce del problema de investigación para la fiabilidad del estudio, por ello se especificaron los siguientes criterios:

- Tener activa una cuenta de Facebook.

- Utilizar con frecuencia la herramienta de chat de la red social Facebook como medio de interacción con otras personas.

- Emplear abreviaturas comunicacionales en la construcción de mensajes.

- Utilizar la red social un tiempo mayor a tres horas diarias.

- Colocar más emoticones que palabras en las conversaciones.

A partir de estos criterios la muestra seleccionada para el desarrollo de esta investigación es de 100 estudiantes. Vale recalcar que los recursos humanos y materiales de este trabajo fueron financiados por el autor del estudio.

\section{RESULTADOS}

Variable: Lenguaje escrito

Dimensión: Construcción de mensaje

Indicador: Respuesta sociocultural de consumo

Técnica: Cambio de rol

Si usted fuera una de las personas que construye mensajes de manera abreviada en la red social Facebook, ¿Cuáles considera que son los factores influyentes para escribir de esa forma?

Vivat Academia. Revista de Comunicación. 15 septiembre 2019 /15 diciembre 2019, nº 148, 41-55 
Sabando Rendón, J. y Rodríguez Caguana, T. Análisis de las abreviaturas comunicacionales del lenguaje escrito en la red social Facebook

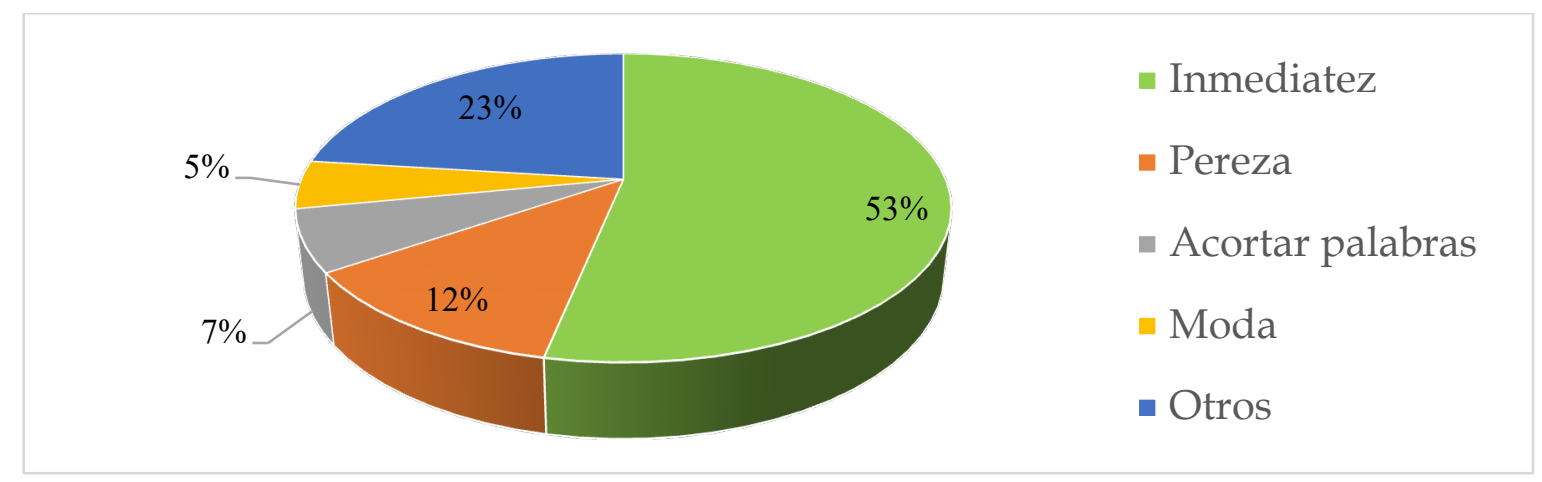

Gráfico 1: Factores influyentes para usar el ciberlenguaje.

Fuente: Elaboración propia.

Análisis: el 40\% de los abordados, considera que la inmediatez es el principal factor influyente en la codificación de mensajes abreviados, pues permite una respuesta rápida. Por otro lado, el $12 \%$ hace referencia a que la pereza juega un papel fundamental dentro de la codificación del mensaje, pues la vaguedad del usuario, lo lleva a configurar la escritura.

Variable: Lenguaje escrito

Dimensión: Recepción de mensaje

Indicador: Decodificación de mensaje

Técnica: Encuesta

¿Puede decodificar mensajes que contengan emoticones en reemplazo de palabras?

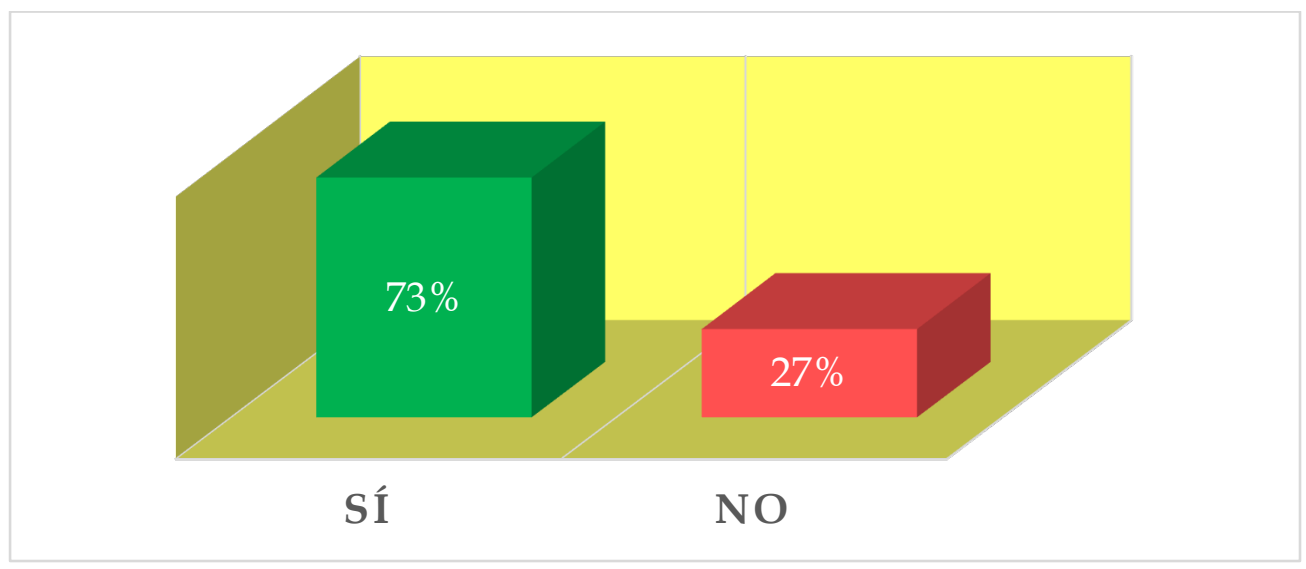

Gráfico 2: Decodificar mensajes que contengan emoticones.

Fuente: Elaboración propia.

Análisis: a diferencia de la decodificación de mensajes abreviados con palabras, el $73 \%$ dice poder descifrar el contenido alterado siempre que lleve emoticones, lo que

Vivat Academia. Revista de Comunicación. 15 septiembre 2019 /15 diciembre 2019, nº 148, 41-55 
evidencia una mayor interpretación del significado de los emojis, frente a la recepción de, únicamente, palabras con lenguaje cibernético. Pese a ello un $27 \%$ del público muestral, indica no lograr entender la información implícita expresada por medio de mensajes abreviados que contengan emoticones.

Variable: Comunicación virtual

Dimensión: Interacción virtual

Indicador: Relaciones interpersonales a partir del chat

Técnica: Escala de puntos

¿Los mensajes emitidos en las relaciones interpersonales por medio del chat son?

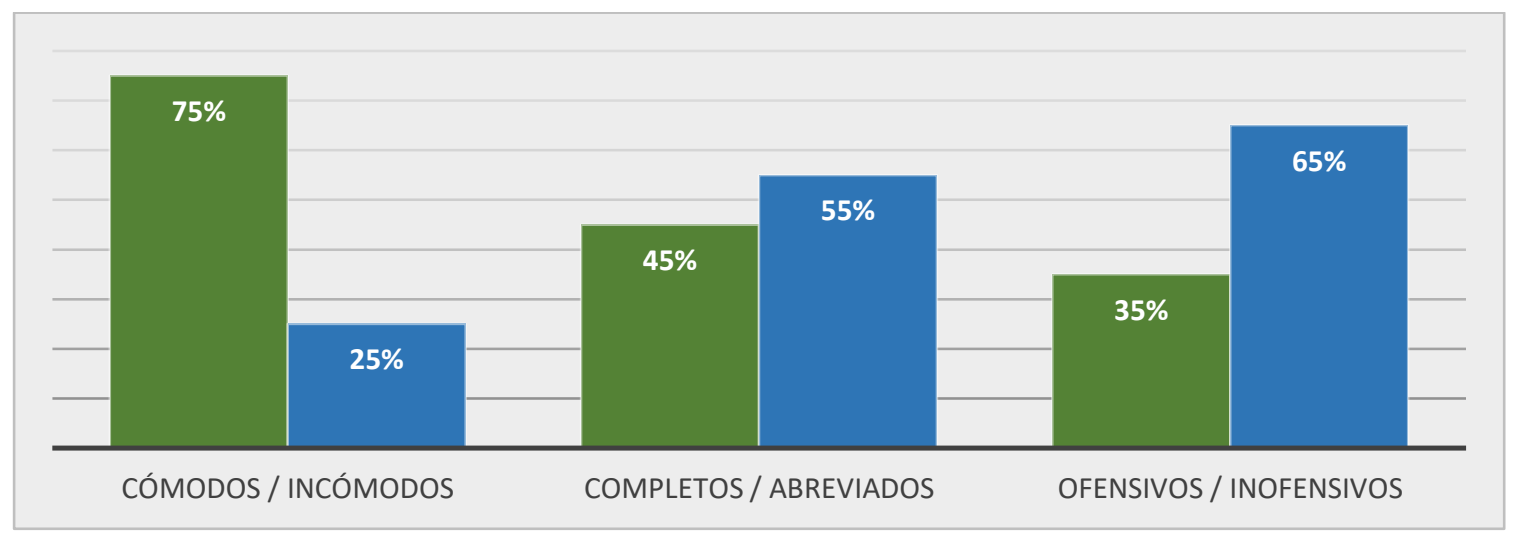

Gráfico 3: Mensajes en relaciones interpersonales.

Fuente: Elaboración propia.

Análisis: en el gráfico se muestra como el $75 \%$ de los estudiantes indican que los mensajes emitidos por medio del chat son cómodos, lo que representa un grado de aceptación por el espacio de interacción de la red social. Por otro lado, el 55\% de los abordados señalan que los mensajes generados son abreviados, siendo un contexto menos formalizado, posibilitando un mayor de tiempo de interacción y una rápida respuesta (inmediatez).

Variable: Comunicación virtual

Dimensión: Ciberlenguaje

Indicador: Abreviaturas comunicacionales

Técnica: Encuesta

¿Los contactos que tiene en la red social Facebook utilizan abreviaturas comunicacionales en las publicaciones o mensajes que le envían?

Vivat Academia. Revista de Comunicación. 15 septiembre 2019 / 15 diciembre 2019, n 148, 41-55 

del lenguaje escrito en la red social Facebook

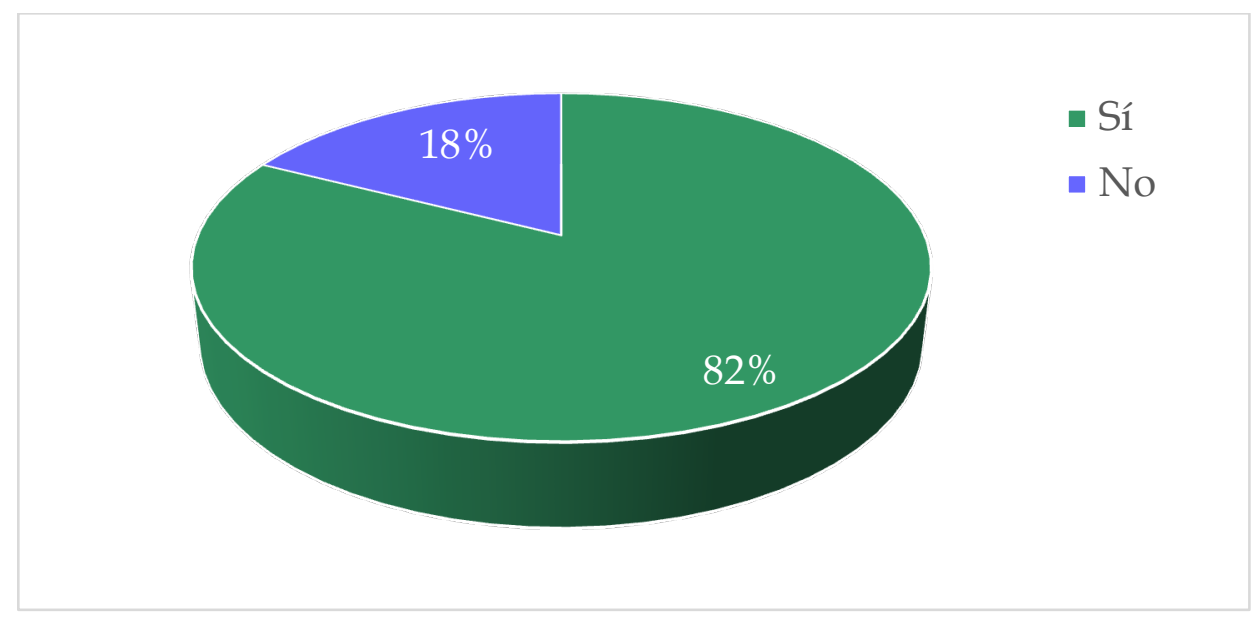

Gráfico 4: Contactos que utilizan el ciberlenguaje.

Fuente: Elaboración propia.

Análisis: como se muestra en el gráfico, el $86 \%$ de los abordados señalaron que los contactos que tienen en la red social Facebook escriben de manera abreviada. Por otro lado, el 14\% indica que sus amigos no emplean ciberlenguaje en las publicaciones, por lo que se infiere siguen todas las normas ortográficas, en la grafía manejada en Facebook.

\section{CONCLUSIONES Y DISCUSIÓN}

El manejo de la red social Facebook ha llevado a los estudiantes abordados de la Unidad Educativa Pedro J. Montero, a la implementación de codificaciones alejadas de las reglas gramaticales, siendo influenciados por la rapidez que exige la transmisión de mensajes dentro de la misma.

El 76\% de los jóvenes hacen uso de abreviaturas comunicacionales por la inmediatez que representa y la agilización en el envío de mensajes, lo que permite un aumento en el tiempo de interacción con el receptor y una respuesta a una mayor velocidad. Junto a ello, el $86 \%$ de los abordados mencionó que sus contactos publican y envían mensajes con alteraciones gramaticales, por lo que ellos deben implementar esa simbología para ser entendidos.

Por otro lado, la decodificación del mensaje con este tipo de codificación, parece no ser un problema para los estudiantes, pues el 59\% de ellos puede descifrar los textos con lenguaje cibernético y, el 73\%, cuando éstos son reemplazados o acompañados con emojis (emoticones), disminuyendo la probabilidad de un mensaje no captado.

$\mathrm{Al}$ ser Facebook una red social, el espacio de chat que maneja su interfaz es atractiva para un gran porcentaje de los abordados siendo más del $66 \%$ quienes se sienten atraídos a usar éste medio para el envío de información a los usuarios.

Vivat Academia. Revista de Comunicación. 15 septiembre 2019 / 15 diciembre 2019, n 148, 41-55 
El desarrollo de la investigación permite sintetizar que, conociendo al lenguaje escrito como un medio comunicativo que, a través de elementos codificados de manera escrita, transmiten información al perceptor, éste es capaz de descifrar los símbolos por medio del aprendizaje de la grafía. Este medio comunicativo es utilizado por los jóvenes dentro de la red social Facebook, permitiendo un el envío ágil de información, pues para ello, no es necesario contar con la presencia de los interlocutores en el mismo espacio.

Sin embargo, las construcciones gramaticales usadas dentro de la red social presentan variaciones, la misma que se denominan ciberlenguaje, siendo esta una forma de escribir, en la cual se reducen las palabras a su más mínima expresión. El uso de este lenguaje cibernético, se debe a la inmediatez en la codificación del mensaje y la agilización en su envío, lo que permite un mayor tiempo de interacción.

A su vez, relacionarse con personas que manejan esta escritura dentro de la red social Facebook, influye en el perceptor, para que éste, utilice los mismos códigos al momento de emitir la respuesta. Todos estos análisis demuestran que la mayoría de los estudiantes, emplean el ciberlenguaje por la inmediatez en la interacción y la interfaz que maneja la red social, siendo una plataforma interactiva y dinámica, donde los usuarios están en constante envío y recepción de información

\section{REFERENCIAS}

Almansa, A. et al. (2013). Redes sociales y jóvenes. Uso de Facebook en la juventud colombiana y española. Revista Comunicar, 40, 127-135.

Berlanga, I. y Martínez, E. (2010). Ciberlenguaje y principios de retórica clásica. Redes sociales: el caso Facebook. Enl@ce Revista Venezolana de Información, Tecnología y Conocimiento, 7(2), 47-61.

Carbone, F. (2016). Ciberlenguaje: Q sean :) s/ importar en q idioma. Recuperado de: http://www.eldiaonline.com/ciberlenguaje-q-sean-s-importar-en-q-idioma/

Colás Bravo, P.; González Ramírez, T. y de Pablos Pons, J. (2013). Juventud y redes sociales: Motivaciones y usos preferentes. Revista Científica de Educomunicación Comunicar, 40, 15-23.

Cortés Campos, R. L. (2015). Uso y consumo de redes sociales virtuales entre estudiantes universitarios. Un acercamiento a los hábitos de multitarea. Revista Iberoamericana de Producción Académica y Gestión Educativa, 2, 1-16.

Fernández, I. (2016). Fenómenos interlingüísticos en estudiantes universitarios foráneos asilados en Madrid. Recuperado de

Vivat Academia. Revista de Comunicación. 15 septiembre 2019 /15 diciembre 2019, n 148, 41-55 
Sabando Rendón, J. y Rodríguez Caguana, T. Análisis de las abreviaturas comunicacionales del lenguaje escrito en la red social Facebook

https://www.academia.edu/21600922/Fen\%C3\%B3menos_interling\%C3\%BC\%C3\% ADsticos_en_estudiantes_universitarios_for\%C3\%A1neos_asilados_en_Madrid?auto =download

González Santamaría, D. M. y González González, M. A. (2014). Lenguajes del poder. El chat en las redes sociales virtuales: lenguaje y libertad. Plumilla Educativa Revista de la Facultad de Ciencias Sociales y Humanas, 14, 57-72.

Ong, W. J. (2006). Oralidad y escritura Tecnología de la palabra. Argentina: Fondo de Cultura Económica.

Pérez, J. e Ibarra, A. (2013). La socialización Mediada en las Interacciones juveniles. La Construcción del Yo en Facebook. Paakat Revista de Tecnología y Sociedad, 3(4), 1-12.

Rincón, C. A. (2011). Oralidad/escritura. Recuperado de http://aprendeenlinea.udea.edu.co/boa/contenidos.php/cb10887d801424883996613 77b684b60/511/estilo/azul_turquesa/1/contenido/capitulos/Unidad8OralidadyEsc ritura.PDF

Ríos, L. (2016). El lenguaje chat 'rejuvenece', pero supone riesgos al idioma. Recuperado de http://www.elheraldo.co/tendencias/el-lenguaje-chat-rejuvenece-pero-suponeriesgos-al-idioma-256388

Rodríguez, Lizeth (2015). Apropiación del ciberlenguaje en jóvenes y adultos. (Trabajo para la obtención de Grado de Doctora en Ciencias Sociales y Humanidad). Universidad Autónoma de Aguascalientes, México.

Vaqueiro Romero, M. (2012). Ciberlenguaje juvenil en las redes sociales. Congreso Iberoamericano de las Lenguas en la Educación y en la Cultura. Recuperado de http://www.oei.es/congresolenguas/comunicacionesPDF/Vaqueiro_Montserrat.pdf

Zapatero Cáceres, M. D.; Brändle, G., y Ruiz San-Román, J. A. (2013). Comunicación interpersonal en la web 2.0. Las relaciones de los jóvenes con desconocidos, en Revista Latina de Comunicación Social, 68, 436-456.

\section{AUTORES}

\section{Jonathan Sabando Rendón}

Licenciado en Ciencias de la Comunicación Social de la Universidad de Guayaquil. Especialista en investigaciones que desarrollen temáticas referidas a construcciones lingüísticas, procesos simbólicos-culturales, y resignificación de lenguajes.

Vivat Academia. Revista de Comunicación. 15 septiembre 2019 /15 diciembre 2019, nº 148, 41-55 
Sabando Rendón, J. y Rodríguez Caguana, T. Análisis de las abreviaturas comunicacionales del lenguaje escrito en la red social Facebook

El autor tiene experiencia en investigaciones de comunicación y cultura, comunicación y desarrollo social. jonathan.sabandor@ug.edu.ec

\section{Tomás Rodríguez Caguana}

Doctorando en filosofía social por la universidad de la Habana. Magister en comunicación. Tres diplomas en comunicación y género. Licenciado en comunicación. Autor, y co-autor de quince artículos científicos en cada uno de los quintiles en que se divide la producción científica. Gestor de investigación de la Facultad de Comunicación Social de la Universidad de Guayaquil. Profesor titular de ésa alma Máter. Profesor invitado de la Universidad de las Artes.

tomas.rodriguezc@ug.edu.ec

Orcid ID: https:// orcid.org/0000-0002-4673-9295

Vivat Academia. Revista de Comunicación. 15 septiembre 2019 / 15 diciembre 2019, nº 148, 41-55 